\title{
Características de carcaça de cordeiros Morada Nova alimentados com diferentes níveis do fruto-refugo de melão em substituição ao milho moído na dieta
}

\author{
Roberto Germano Costa ${ }^{1}$, Cláudio Adriano Correia de Lima ${ }^{2}$, Ariosvaldo Nunes de Medeiros ${ }^{1}$, \\ Guilherme Ferreira da Costa Lima ${ }^{2}$, Carlo Aldrovandi Torreão Marques ${ }^{3}$, Neube Michel dos Santos ${ }^{4}$ \\ ${ }^{1}$ Universidade Federal da Paraíba - UFPB, Bolsista do CNPq. \\ 2 Empresa de Pesquisa Agropecuária do Rio Grande do Norte-EMPARN. \\ 3 Universidade Federal do Piauí-UFPI, Campus de Bom Jesus-PI. \\ ${ }^{4}$ Agência Estadual de Vigilância Sanitária - AGEVISA/PB e Doutorando do Programa de Doutorado Integrado em Zootecnia - PDIZ/UFPB.
}

RESUMO - Foram avaliados as características de carcaça e os rendimentos dos cortes comerciais e realizada avaliação tecidual de 20 cordeiros Morada Nova alimentados com dietas contendo fruto-refugo de melão em substituição a 0, 30, 60 ou 100\% do milho moído. Os animais, com peso médio inicial de $15 \mathrm{~kg}$ e 6 meses de idade, foram mantidos confinados em baias individuais e abatidos com peso médio de $26 \mathrm{~kg}$. Utilizou-se um delineamento experimental inteiramente casualizado, com quatro tratamentos (níveis de substituição do milho por fruto-refugo de melão) e cinco repetições. Não foram observadas diferenças significativas no peso de corpo vazio, no peso de carcaça quente e fria, nos rendimentos de carcaça quente e fria nem no rendimento biológico. Também não foi verificado efeito significativo da inclusão de frutorefugo de melão nas dietas sobre os rendimentos dos cortes comerciais (pescoço, costela, paleta, lombo e a perna) e as concentrações de músculo, osso e gordura. A substituição do milho moído por fruto-refugo do melão nas dietas não prejudica as características quantitativas de carcaça de cordeiros Morada Nova e consiste numa boa alternativa na alimentação de ovinos de corte em terminação.

Palavras-chave: abate, carne, composição tecidual, gordura, músculo

\section{Carcass traits of Morada Nova lambs fed different levels of melon fruit- refuse in substitution of ground corn in the diet}

\begin{abstract}
This experiment evaluated carcass traits and yields of comercial cuts and tissue evaluation of 20 Morada Nova lambs fed diets with fruit-refuse of melon replacing 0, 30, 60 or $100 \%$ of ground corn. The animals with $15 \mathrm{~kg}$ of initial body weight and at 6 six months of age were kept confined in individual pens and slaughtered with $26 \mathrm{~kg}$ of weight. It was used a completely randomized experimental design, with four treatments (levels of ground corn replaced by melon fruit-refuse) and five replicates. It was not observed any significant differences for empty body weight, hot and cold carcass weight, yields of hot and cold carcass, and biological yield. Neither it was noted significant effect of inclusion of melon fruit-refuse in the diets on yields of commercial cuts (neck, rib, palette, loin and leg) and concentrations of muscle, bone and fat. Substitution of ground corn by melon fruit-refuse in diets does not harm quantitative traits of carcass of Morada Nova lambs and it is a good alternative for finishing meat sheep feeding.
\end{abstract}

Key Words: fat, meat, muscle, slaughter, tissue composition

\section{Introdução}

A ampliação do mercado de carne ovina no Brasil permitiu, nos últimos anos, expressivo desenvolvimento da ovinocultura de corte no País e consolidou a atividade produtiva como importante setor de geração de emprego e renda (Carvalho, 2003).

Atualmente, cerca de 58\% do rebanho ovino brasileiro encontra-se na Região Nordeste (IBGE, 2008). O rebanho caracteriza-se por apresentar baixos índices produtivos, possivelmente em decorrência do sistema extensivo de produção empregado e da indisponibilidade de forragens durante a maior parte do ano. A terminação de cordeiros em confinamento representa uma alternativa para viabilizar a existência de sistemas produtivos mais eficientes (Oliveira et al., 2003). Entretanto, a utilização indiscriminada de concentrados na dieta dos cordeiros, além de aumentar os custos de produção, eleva a possibilidade de ocorrência de 
distúrbios fisiológicos nos animais. Portanto, a busca por alternativas de alimentos de baixo custo que promovam melhor relação custo-benefício e maior lucratividade ao produtor, sem piorar as características de carcaça, representa a alavanca propulsora da atividade na Região (Costa et al., 2008).

Towsend et al. (2001) sugeriram a utilização de subprodutos da agroindústria como alternativa para a redução dos custos com alimentação. Várias pesquisas têm sido realizadas objetivando a substituição total ou parcial de concentrados na dieta por subprodutos na alimentação animal (Scerra et al., 2001; Lanza et al., 2003; Alcaide et al., 2003; Anrique, 2003; Rahman \& Huque, 2002).

O cultivo do melão irrigado na região semi-árida brasileira é uma das atividades agrícolas de maior expressão socioeconômica presentes nos estados de Pernambuco, Bahia, Paraíba, Ceará e Rio Grande do Norte (Dias et al., 1998). O mercado interno absorve cerca de $70 \%$ da produção de melão e o externo $20 \%$, enquanto os $10 \%$ restantes são considerados frutos-refugo. Considerando os altos índices produtivos alcançados, a quantidade de frutos-refugo representa disponibilidade estimada de 34.950 t/ano de matéria natural (Manterola et al., 1992) e caracteriza-se como opção para a suplementação de ruminantes no período de escassez de alimentos no semiárido brasileiro, em razão de sua disponibilidade e qualidade nutricional (rico em carboidratos não fibrosos e água). Este trabalho foi realizado com o objetivo de avaliar os efeitos da inclusão do fruto-refugo do melão em substituição ao milho moído na dieta sobre as características de carcaça de cordeiros Morada Nova.

\section{Material e Métodos}

O experimento foi conduzido na Estação Experimental da EMPARN, Terras Secas-RN, no período de janeiro a maio de 2006, época da águas. O clima da reclassifica-se como tropical quente e a precipitação média anual aproxima-se dos $473 \mathrm{~mm}$.
Foram utilizados 20 cordeiros da raça Morada Nova oriundos de um ensaio de desempenho com 32 animais (20 machos e 12 fêmeas), com idade média de seis meses e peso inicial de $15 \mathrm{~kg}$, confinados em baias individuais providas de comedouros, bebedouros e saleiros. Os animais foram pesados, identificados, vermifugados e distribuídos em delineamento inteiramente casualizado, com quatro tratamentos, cada um com cinco repetições, representados pela substituição do milho moído por fruto-refugo de melão em 0, 30, 60 e 100\% na matéria seca das dietas. As pesagens ocorreram a cada sete dias, até o abate, para acompanhamento do desenvolvimento corporal dos animais.

As análises de composição bromatológica dos alimentos (Tabela 1), das sobras e fezes dos animais foram realizadas no Laboratório de Nutrição Animal do Departamento de Zootecnia da Universidade Federal da Paraíba e no Laboratório de Nutrição Animal do Departamento de Agropecuária da Universidade Federal do Rio Grande do Norte utilizando-se a metodologia descrita por Silva \& Queiroz (2002) para determinação dos teores de matéria seca (MS), matéria mineral (MM), proteína bruta (PB), extrato etéreo (EE) e lignina em detergente ácido (LDA) e a metodologia descrita por Van Soest et al. (1991) e recomendada pelo fabricante do aparelho ANKON Technology para determinação do conteúdo de fibra em detergente neutro (FDN) e fibra em detergente ácido (FDA). Os teores de compostos nitrogenados insolúveis em detergente neutro (NIDN) e em detergente ácido (NIDA) foram obtidos nos resíduos da FDN e FDA, pelo procedimento de micro Kejdahl.

As dietas (Tabela 2) foram calculadas para atendimento às exigências em proteína bruta e energia metabolizável para ganhos de $150 \mathrm{~g} /$ dia, de acordo com recomendações contidas no NRC (1985), e fornecidas duas vezes ao dia, de forma a permitir consumo ad libitum com $10 \%$ de sobras. Os frutos utilizados na pesquisa eram cortados em pedaços de 2 a 3 $\mathrm{cm}^{2}$ in natura e adicionados aos demais alimentos no momento de oferta aos animais e foram provenientes do

Tabela 1 - Composição bromatológica dos ingredientes da dieta

\begin{tabular}{|c|c|c|c|c|c|}
\hline & & & Ingrediente & & \\
\hline & Milho moído & Melão & Farelo de soja & Torta de algodão & Feno de capim-elefante \\
\hline Matéria seca (\%) & 89,35 & 7,28 & 89,62 & 94,14 & 89,64 \\
\hline Matéria mineral (\%) & 1,38 & 9,30 & 6,95 & 4,92 & 7,49 \\
\hline Matéria orgânica (\%) & 98,62 & 90,70 & 93,05 & 95,08 & 92,51 \\
\hline Proteína bruta (\%) & 7,67 & 11,58 & 43,46 & 25,84 & 4,28 \\
\hline Extrato etéreo (\%) & 3,19 & 7,62 & 3,23 & 9,60 & 0,80 \\
\hline Fibra em detergente neutro (\%) & 16,00 & 20,58 & 26,76 & 54,31 & 78,88 \\
\hline Carboidratos não-fibrosos (\%) & 71,76 & 49,36 & 19,60 & 5,33 & 8,55 \\
\hline Lignina (\%) & 1,27 & 5,86 & 1,23 & 4,18 & 5,26 \\
\hline
\end{tabular}


Tabela 2 - Composição das dietas experimentais

\begin{tabular}{|c|c|c|c|c|}
\hline \multirow[t]{2}{*}{ Ingrediente (\% na MS) } & \multicolumn{4}{|c|}{ Nível de fruto-refugo de melão em substituição ao milho (\%) } \\
\hline & 0 & 30 & 60 & 100 \\
\hline Milho moído & 29,00 & 20,30 & 11,60 & - \\
\hline Melão (fruto) & - & 8,70 & 17,40 & 29,00 \\
\hline Farelo de soja & 26,50 & 25,50 & 24,60 & 23,50 \\
\hline Torta de algodão & 3,0 & 4,0 & 4,90 & 6,00 \\
\hline Feno de capim-elefante & 40,0 & 40,00 & 40,00 & 40,00 \\
\hline Mistura mineral $^{1}$ & 1,5 & 1,5 & 1,5 & 1,5 \\
\hline \multicolumn{5}{|l|}{ Composição (\%) } \\
\hline Matéria seca & 89,83 & 82,73 & 75,64 & 66,17 \\
\hline Matéria orgânica & 93,11 & 92,42 & 91,77 & 89,83 \\
\hline Proteína bruta & 16,90 & 16,76 & 16,66 & 16,55 \\
\hline Extrato etéreo & 2,40 & 2,83 & 3,28 & 3,92 \\
\hline Fibra em detergente neutro & 44,91 & 45,58 & 46,23 & 47,06 \\
\hline Fibra em detergente ácido & 26,78 & 27,56 & 28,34 & 29,36 \\
\hline Carboidratos totais & 75,32 & 74,37 & 73,34 & 71,92 \\
\hline Carboidratos não-fibrosos & 30,41 & 28,79 & 27,11 & 24,86 \\
\hline Lignina & 2,49 & 3,07 & 3,46 & 4,37 \\
\hline Matéria mineral & 5,38 & 6,04 & 6,72 & 7,61 \\
\hline Nutrientes digestíveis totais & 72,66 & 66,66 & 60,61 & 55,40 \\
\hline Energia metabolizável (Mcal de EM/kg de MS) ${ }^{2}$ & 2,60 & 2,53 & 2,45 & 2,35 \\
\hline
\end{tabular}

descarte da primeira seleção que ocorre no campo e dos frutos refugados na linha de embalagem, em ofertas semanais.

Para estimativa dos carboidratos totais (CT), utilizou-se a equação proposta por Sniffen et al. (1992), CT = 100-(\%PB + \%EE + \%MM), ao passo que os teores de carboidratos nãofibrosos (CNF) foram estimados pela diferença entre o conteúdos de carboidratos totais e FDN. O consumo de nutrientes digestíveis totais (NDT) foi calculado segundo Sniffen et al. (1992), cNDT = (cPB-PBf) +2,25*(cEE-Eef $)+$ (cCT - CTf), em que cPB, cEE e cCT significam, respectivamente, consumo de proteína bruta, extrato etéreo e carboidratos totais, enquanto $\mathrm{PBf}$, EEf e CTf referem-se às excreções de PB, EE e carboidratos totais nas fezes. Os nutrientes digestíveis totais (NDT) foram calculados pela equação proposta por Weiss (1999): NDT = [(DVPB + DVFDN +(DVEE*2,5)]-7, em queDVPB, DVFDNeDVEE significam, respectivamente, a digestibilidade verdadeira de PB, FDN e EE. A energia metabolizável foi obtida transformando o NDT em energia digestível (ED), por meio da equação $\mathrm{ED}=(\mathrm{NDT}) / 100) \times 4,409$, e posteriormente a ED em energia metabalizável pela equação $\mathrm{EM}=\mathrm{ED} \times 0,082$, segundo o NRC(1989).

Quando os animais atingiram o peso estimado para o abate, foram submetidos a jejum de sólidos e líquidos por 16 horas, resultando em peso médio de $26 \mathrm{~kg}$. Transcorrido esse período, pesaram-se novamente os animais para obtenção do peso vivo ao abate (PVA) e do percentual de perda de peso durante o jejum $(\mathrm{PJ}=(\mathrm{PV}-\mathrm{PVA}) \times 100 / \mathrm{PV})$.
O abate foi realizado em concordância com as normas vigentes do Regulamento de Inspeção Industrial e Sanitária dos Produtos de Origem Animal (Brasil, 1952). As carcaças foram penduradas pelos tendões em ganchos apropriados, distanciadas $17 \mathrm{~cm}$ uma da outra e resfriadas em câmara frigorífica a temperatura de $4^{\circ} \mathrm{C}$ por 24 horas. Registraram-se, antes do processo de resfriamento, o peso de carcaça quente (PCQ), o peso da gordura pélvica-renal e o rendimento de carcaça quente $($ RCQ $=$ PCQ $/$ PVA $\times 100) . O$ trato gastrintestinal (TGI) foi pesado ainda cheio e após a retirada de seu conteúdo, determinando-se, em seguida, o peso de corpo vazio (PCV) e o rendimento verdadeiro ou biológico $(\mathrm{RB}=\mathrm{PCQ} / \mathrm{PCV} \times 100)$.

Após o processo de resfriamento, determinaram-se o peso de carcaça fria (PCF), o rendimento da carcaça fria $(\mathrm{RCF}=\mathrm{PCF} / \mathrm{PVA} \times 100)$ e a perda por resfriamento $(\mathrm{PPR}=$ PCQ - PCF/PCQ × 100), bem como o índice de compacidade da carcaça $($ ICC $=$ PCF/comprimento interno da carcaça fria, tomado no bordo anterior da primeira costela até o bordo anterior da sínfise isquiopubiana). Em seguida, as carcaças foram seccionadas e as meias-carcaças pesadas. A meiacarcaça esquerda foi seccionada em cinco regiões anatômicas ou cortes comerciais (perna, paleta, lombo, costela e pescoço), em concordância com a metodologia proposta por Silva Sobrinho et al. (2005).

Na porção dorsal do músculo longissimus dorsi e por intermédio de um paquímetro, foram mensuradas quatro medidas: A - largura máxima do músculo; B - profundidade 
máxima do músculo; C - espessura mínima de gordura de cobertura sobre o músculo e GR - espessura máxima de gordura de cobertura sobre a superfície da $13^{\underline{a}}$ costela. A área de olho-de-lombo foi calculada utilizando-se a fórmula: $\mathrm{AOL}=(\mathrm{A} / 2 \times \mathrm{B} / 2) \times \pi$ (Silva Sobrinho et al., 2005).

As pernas, após pesagem e identificação, foram acondicionadas em sacos plásticos e congeladas para posterior dissecação, que foi realizada para determinar as proporções de músculo, osso e gordura (subcutânea, intramuscular e total), segundo metodologia de Brown \& Willians (1979), assim como a relação músculo:osso e músculo:gordura e o índice de musculosidade da perna, calculado pela fórmula descrita por Purchas et al. (1991).

Efetuaram-se análises de variância e de regressão dos dados relativos aos pesos e rendimentos encontrados, bem como dos resultados das proporções de músculo, osso e gordura, utilizando-se o peso de abate como covariável. A escolha dos modelos baseou-se na significância dos coeficientes lineares e quadráticos, por meio do teste t de “Student”, para o nível de 5\% de probabilidade (SAS, 1999).

\section{Resultados e Discussão}

A inclusão do fruto-refugo de melão em substituição ao milho moído na dieta não influenciou $(\mathrm{P}>0,05)$ as características de carcaça (Tabela 3) dos cordeiros, provavelmente em virtude do procedimento metodológico empregado, uma vez que, previamente, estabeleceu-se um peso vivo para o abate de $26 \mathrm{~kg}$. Resultados semelhantes foram encontrados por Lanza et al. (2003), em pesquisa na qual avaliaram a inclusão de ervilhas na dieta de cordeiros, e por Gonzaga Neto et al. (2006), em pesquisa com diferentes relações volumoso:concentrado na dieta de cordeiros Morada Nova. O ganho de peso diário dos animais apresentou tendência linear decrescente $(\mathrm{P}<0,05)$, embora apenas o nível de $100 \%$ de substituição tenha promovido ganho de peso abaixo dos $150 \mathrm{~g}$ estimados para a dieta.

A substituição de milho por melão na alimentação de cordeiros Morada Nova não influenciou os pesos médios dos cortes comerciais nem seus rendimentos (Tabela 4). Essa semelhança pode ser atribuída à lei da harmonia anatômica (Boccard \& Dumont, 1960) de que carcaças com pesos e concentrações de gordura similares apresentam praticamente todas as regiões corporais em proporções semelhantes, independentemente da conformação dos genótipos considerados.

Os teores de gordura subcutânea, intramuscular e total não foram influenciados pela redução dos níveis de milho na dieta dos cordeiros (Tabela 5). Normalmente, a variação proposital nos níveis de concentrado fornecidos aos ruminantes interfere diretamente no metabolismo lipídico do animal e, portanto, na quantidade de tecido gorduroso

Tabela 3 - Características de carcaça de cordeiros Morada Nova alimentados com dietas contendo fruto-refugo de melão

\begin{tabular}{|c|c|c|c|c|c|c|}
\hline \multirow[t]{2}{*}{ Variáveis } & \multicolumn{4}{|c|}{ Nível de substituição do milho por fruto-refugo de melão (\%) } & \multirow[t]{2}{*}{ CV (\%) } & \multirow[t]{2}{*}{ Equação de regressão } \\
\hline & $0 \%$ & $30 \%$ & $60 \%$ & $100 \%$ & & \\
\hline Peso antes do jejum (kg) & 26,73 & 27,97 & 28,12 & 27,84 & 6,05 & $\hat{Y}=27,66$ \\
\hline Peso vivo ao abate (kg) & 25,34 & 27,16 & 27,17 & 26,70 & 5,73 & $Y=26,59$ \\
\hline Peso do corpo vazio (kg) & 23,51 & 24,13 & 24,26 & 23,81 & 4,59 & $\hat{Y}=23,86$ \\
\hline Peso da carcaça quente (kg) & 11,46 & 12,29 & 12,24 & 12,10 & 6,61 & $\hat{Y}=12,02$ \\
\hline Peso da carcaça fria (kg) & 10,88 & 11,53 & 11,55 & 11,41 & 6,87 & $\hat{Y}=11,34$ \\
\hline Rendimento de carcaça quente (\%) & 44,72 & 45,33 & 45,03 & 45,30 & 2,01 & $Y=45,10$ \\
\hline Rendimento de carcaça fria (\%) & 41,95 & 43,82 & 42,47 & 42,70 & 3,85 & $\hat{Y}=42,74$ \\
\hline Rendimento biológico (\%) & 50,11 & 50,97 & 50,40 & 50,80 & 3,56 & $\hat{Y}=50,57$ \\
\hline Perda no jejum (\%) & 3,74 & 2,89 & 3,37 & 4,09 & 23,75 & $\hat{Y}=2,62$ \\
\hline Ganho de peso diário (g) & 163 & 147 & 150 & 133 & 15,86 & $Y=161-0,0003 x$ \\
\hline
\end{tabular}

CV - coeficiente de variação.

Tabela 4 - Pesos e rendimentos dos cortes comerciais da carcaça de corderios Morada Nova alimentados com dietas contendo fruto-refugo de melão

\begin{tabular}{|c|c|c|c|c|c|c|}
\hline \multirow[t]{2}{*}{ Rendimento dos cortes } & \multicolumn{4}{|c|}{ Nível de substituição do milho por fruto-refugo de melão (\%) } & \multirow[t]{2}{*}{ CV $(\%)$} & \multirow[t]{2}{*}{ Equação de regressão } \\
\hline & $0 \%$ & $30 \%$ & $60 \%$ & $100 \%$ & & \\
\hline Peso da meia-carcaça fria (g) & 5405,00 & 6148,00 & 5726,00 & 5568,00 & 8,00 & $\mathrm{Y}=5712,00$ \\
\hline Paleta (\%) & 20,13 & 19,37 & 19,64 & 20,50 & 7,02 & $Y=19,91$ \\
\hline Perna (\%) & 32,70 & 31,51 & 33,77 & 31,13 & 4,55 & $Y=32,29$ \\
\hline Lombo (\%) & 11,53 & 11,29 & 12,35 & 12,41 & 10,71 & $\mathrm{Y}=11,89$ \\
\hline Costela (\%) & 26,26 & 26,61 & 23,65 & 25,52 & 12,75 & $Y=25,51$ \\
\hline Pescoço (\%) & 9,39 & 11,22 & 10,59 & 10,44 & 15,38 & $Y=10,41$ \\
\hline
\end{tabular}

CV - coeficiente de variação. 
depositado na carcaça. Contudo, essa constatação não foi confirmada nesta pesquisa, possivelmente, em virtude da semelhança na idade e no peso de abate dos animais.

As relações músculo:osso e músculo:gordura encontradas neste experimento não foram significativamente afetadas pela inclusão do fruto-refugo de melão na dieta dos animais. De acordo com Oliveira et al. (2002), a interpretação correta das relações entre os tecidos (adiposo, muscular e ósseo) é fundamental para se estabelecer mecanismos de comparação, necessários para nortear possíveis programas de seleção, além de possibilitar a determinação de pontos ideais de abate (idade e ou peso vivo para abate), favoráveis à obtenção de carcaças de qualidade desejável ao mercado consumidor.

A medida da área de olho-de-lombo não diferiu entre os níveis de melão utilizados nas dietas. O valor médio foi de $10,11 \mathrm{~cm}^{2}$ (Tabela 6), superior ao encontrado por Gonzaga Neto et al. (2006), que obtiveram $6,3 \mathrm{~cm}^{2}$ para animais abatidos com peso vivo inferior ao estabelecido neste trabalho. Segundo Silva Sobrinho et al. (2005), o músculo longissimus dorsi, por ser de maturação tardia, é indicado para estimar a musculosidade total do animal em relação aos demais tecidos presente na carcaça. De acordo com Cunha et al. (2000), a área de olho-de-lombo é positivamente correlacionada ao peso vivo ao abate.

Os índices de compacidade encontrados neste trabalho indicaram boa proporção de tecido muscular por unidade de comprimento se comparados aos valores obtidos em pesquisas com genótipos distintos e com maior porte. Reis et al. (2001) observaram $0,21 \mathrm{~kg} / \mathrm{cm}$ para o índice de compacidade da carcaça em mestiços de Bergamácia $\times$ Corridale, enquanto Cunha et al. (2000) verificaram valores médios de $0,25 \mathrm{~kg} / \mathrm{cm}$ para cordeiros Ile de France $\times$ Ideal. Siqueira et al. (2001), avaliando cordeiros Ile de France $\times$ Corridale, abatidos com $28 \mathrm{~kg}$ de peso vivo, obtiveram valor para índice de compacidade da carcaça de $0,26 \mathrm{~kg} / \mathrm{cm}$.

Tabela 5 - Composição tecidual e índice de musculosidade da perna de cordeiros Morada Nova alimentados com dietas contendo frutorefugo de melão

\begin{tabular}{|c|c|c|c|c|c|c|}
\hline \multirow[t]{2}{*}{ Variável } & \multicolumn{4}{|c|}{ Nível de substituição do milho por fruto-refugo de melão (\%) } & \multirow[t]{2}{*}{ CV (\%) } & \multirow[t]{2}{*}{ Equação de regressão } \\
\hline & $0 \%$ & $30 \%$ & $60 \%$ & $100 \%$ & & \\
\hline Músculo (g) & 1156,00 & 1292,00 & 1298,00 & 1125,00 & 9,66 & $Y=1218,00$ \\
\hline Gordura subcutânea (g) & 113,00 & 132,00 & 118,00 & 124,00 & 24,43 & $Y=121,75$ \\
\hline Gordura intramuscular (g) & 38,00 & 36,00 & 44,00 & 36,00 & 26,29 & $Y=38,50$ \\
\hline Gordura total (g) & 170,00 & 194,00 & 188,00 & 182,00 & 21,57 & $Y=183,50$ \\
\hline Osso (g) & 438,00 & 446,00 & 448,00 & 428,00 & 12,97 & $Y=440,00$ \\
\hline Outros tecidos (g) & 296,00 & 368,00 & 358,00 & 309,00 & 17,85 & $Y=333,00$ \\
\hline Músculo (\%) & 65,47 & 66,86 & 67,14 & 64,87 & 3,18 & $Y=66,08$ \\
\hline Osso $(\%)$ & 24,81 & 23,08 & 23,04 & 24,61 & 6,94 & $Y=23,89$ \\
\hline Gordura (\%) & 9,69 & 10,06 & 9,82 & 10,52 & 23,03 & $\mathrm{Y}=10,02$ \\
\hline Relação músculo:osso & 2,64 & 2,90 & 2,94 & 2,65 & 8,70 & $Y=2,78$ \\
\hline Relação músculo:gordura & 7,36 & 6,69 & 7,17 & 6,57 & 27,55 & $Y=6,95$ \\
\hline Índice de musculosidade da perna & 0,38 & 0,40 & 0,48 & 0,38 & 12,65 & $Y=0,41$ \\
\hline
\end{tabular}

$\mathrm{CV}=$ coeficiente de variação.

Tabela 6 - Mensuração do músculo longissimus dorsi, comprimento interno da carcaça e índice de compacidade da carcaça de cordeiros Morada Nova alimentados com dietas com fruto-refugo de melão

\begin{tabular}{|c|c|c|c|c|c|c|}
\hline \multirow[t]{2}{*}{ Variáveis } & \multicolumn{4}{|c|}{ Nível de substituição do milho por fruto-refugo de melão (\%) } & \multirow[t]{2}{*}{ CV (\%) } & \multirow[t]{2}{*}{ Equação de regressão } \\
\hline & $0 \%$ & $30 \%$ & $60 \%$ & $100 \%$ & & \\
\hline Medida de A (cm) & 4,86 & 5,48 & 5,36 & 5,56 & 10,09 & $Y=5,32$ \\
\hline Medida de B (cm) & 2,48 & 2,40 & 2,74 & 2,12 & 10,10 & $Y=2,44$ \\
\hline Medida de C (cm) & 0,10 & 0,10 & 0,14 & 0,10 & 24,89 & $\mathrm{Y}=0,11$ \\
\hline Espessura de gordura (cm) & 0,30 & 0,30 & 0,34 & 0,30 & 8,83 & $\mathrm{Y}=0,31$ \\
\hline Área de olho-de-lombo $\left(\mathrm{cm}^{2}\right)$ & 9,43 & 10,32 & 11,34 & 9,26 & 11,38 & $\mathrm{Y}=10,11$ \\
\hline Comprimento interno da carcaça $(\mathrm{cm})$ & 52,20 & 53,40 & 51,90 & 52,80 & 2,73 & $Y=52,57$ \\
\hline Índice de compacidade da carcaça & 0,21 & 0,22 & 0,22 & 0,22 & 6,81 & $Y=0,22$ \\
\hline
\end{tabular}

$\overline{\mathrm{CV}}=$ coeficiente de variação.

\section{Conclusões}

A substituição do milho moído por fruto-refugo do melão em dietas para cordeiros Morada Nova não provoca alterações nas características quantitativas da carcaça, portanto , essa alternativa alimentar deve ser recomendada, desde que seu preço seja economicamente viável. 


\section{Referências}

ALCAIDE, E.M.; RUIZ, D.Y.; MOUMEN, I.G. Chemical composition and nitrogen availability for goats of sheep of some olive by-products. Small Ruminant Research, v.49, n.3, p.329-336, 2003.

ANRIQUE, R. Efectos de la pulpa de manzana ensilada en la ración de vacas lecheras sobre el consumo, la tasa de sustitución y la producción de leche. Archivos de medicina veterinária, v.35, n.1, p.13-22, 2003.

BOCCARD, R.; DUMONT, B.L. Etude de la production de la viande chez les ovins. II. Variation de l'importance relative dês diferentes régions corporelles de l'agneau de boucherie. Annales de Zootechnie, v.9, n.4, p.355-365, 1960.

BRASIL. MINISTÉRIO DA AGRICULTURA. Regulamento da Inspeção industrial e Sanitária de Produtos de Origem Animal. Brasília, DF: 1952. 154p.

BROWN, A.J.; WILLIAMS, D.R. Sheep carcass evaluation: measurement of composition using a standardized butchery method. Langford: Agricultural Research Council; Meat Research Council, 1979. 16p. (Memorandum, 38).

CARVAlHO, R.B. Potencialidades dos mercados para os produtos derivados de caprinos e ovinos. Disponível em: $<$ www.capritec.com.br>. Acesso em: 6/11/2003.

COSTA, R.G.; MEDEIROS, A.N.; SANTOS, N.M. et al. Qualidade da carcaça de caprinos Saanen alimentados com diferentes níveis de volumoso e concentrado. Revista Brasileira de Ciências Agrárias, v.3, n.2, p.186-190, 2008.

CUNHA, E.A; SANTOS, L.E.; BUENO, M.S et al. Utilização de carneiros de raças de corte para obtenção de cordeiros precoces para abate em plantéis produtores de lã. Revista Brasileira de Zootecnia, v.29, n.1, p.2243-252, 2000.

DIAS, R.C.S.; COSTA, N.D.; CERDAN, C. et al. Cadeia produtiva do melão no Nordeste. In: CASTRO A.M.G.; LIMA, S.M.V.; GOEDERT, W.J. et al. (Eds.) Cadeias produtivas e sistemas naturais: Prospecção Tecnológica. Brasília: SPI, 1998. p.440-493.

GONZAGA NETO, S.; SILVA SOBRINHO, A.G.; ZEOLA, N.M.B.L. et al. Características quantitativas da carcaça de cordeiros deslanados Morada Nova em função da relação volumoso:concentrado na dieta. Revista Brasileira de Zootecnia, v.35, n.4, p.1487-1495, 2006.

INSTITUTO BRASILEIRO DE GEOGRAFIA E ESTATÍSTICA IBGE. [2005]. Pesquisa pecuária municipal. Disponível em: <http://www.ibge.gov.br>. Acesso em: 24/11/2008.

LANZA, M.; BELLA, M.; PRIOLO, A. et al. Peas (Pisum sativum L.) as an alternative protein source in lamb diets: growth performances, and carcass and meat quality. Small Ruminant Research, v.47, n.1, p.63-68, 2003.
MANTEROLA, H.B.; CERDA, D.A.; PORTE, E.F. et al. Valor nutritivo y uso de subproductos agroindustriales y forrages toscos en la alimentación de bovinos. In: SIMPÓSIO SOBRE UTILIZAÇÃO DE SUBPRODUTOS AGROINDUSTRIAIS E RESÍDUOS DE COLHEITA NA ALIMENTAÇÃO DE RUMINANTES, EMPRAPA, UEPAE, São Carlos. Anais... São Carlos, 1992. 351p.

NATIONAL RESEARCH COUNCIL - NRC. Nutrient requirements of sheep. Washington, D.C.: National Academy Press, 1985. $99 \mathrm{p}$.

OLIVEIRA, M.V.M.; PÉREZ, J.R.O.; ALVES, E.L. Avaliação da composição de cortes comerciais, componentes corporais e órgãos internos de cordeiros confinados e alimentados com dejetos de suínos. Revista Brasileira de Zootecnia, v.31, n.3, p.1459-1468, 2002.

OLIVEIRA, M.V.M.; PÉREZ, J.R.O.; GARCIA, I.F.F. et al. Desempenho de cordeiros das raças Bergamácia e Santa Inês, terminadas em confinamento recebendo dejetos de suínos como parte da dieta. Revista Brasileira de Zootecnia, v.32, n.6, p.1391-1396, 2003.

PURCHAS, R.W.; DAVIES, A.S.; ABDUlLAH, A.Y. An objective measure of muscularity: changes with animal growth and differences between genetic lines of southdown sheep. Meat Science, v.30, p.81-94, 1991.

RAMAN, M.M.; HUQUE, K.S. Study on voluntary intake digestibility of banana foliage as cattle feed. Journal of Biological Sciences, v.2, n.1, p.49-52, 2002

REIS, W.; JOBIM, C.C.; MACEDO, F.A.F. et al. Características da carcaça de cordeiros alimentados com dietas contendo grãos de milho conservados em diferentes formas. Revista Brasileira de Zootecnia, v.30, n.4, p.1308-1315, 2001.

SCERRA, V.; CAPARRA, P.; FOTI, F. et al. Citrus pulp and wheat straw silage as ingredient in lamb diets: effects of growth and carcass and meat quality. Small Ruminant Research, v.40, n.1, p.51-56, 2001.

SILVA SOBRINHO, A.G.; PURCHAS, R.W.; KADIM, I.T et al. Musculosidade e composição da perna de ovinos de diferentes genótipos e idades de abate. Pesquisa Agropecuária Brasileira, v.40, n.11, p.1129-1134, 2005.

SIQUEIRA, E.R.; SIMÕES, C.D.; FERNANDES, S. Efeito do sexo e do peso ao abate sobre a produção de carne de cordeiro. Morfometria da carcaça, pesos dos cortes, composição tecidual e componentes não-constituintes da carcaça. Revista Brasileira de Zootecnia, v.30, n.4, p.1299-1307, 2001.

STATISTICAL ANALYSES SYSTEM - SAS. SAS User's guide: Statistics. Version 8 (TS MO). Cary: 1999. 513p.

TOWSEND, C.R.; MAGALHÃES, J.A.; COSTA, N.L. Casca de café na alimentação de ovinos deslanados. Revista Científica de Produção Animal, v.3, n.1, p.55-59, 2001. 